\title{
A influência dos métodos de ensino-aprendizagem-treinamento no conhecimento tático processual no futsal
}

\author{
Valmo José Penna Moreira \\ Cristino Julio Alves da Silva Matias \\ Pablo Juan Greco

\begin{abstract}
Centro de Estudos de Cognição e Ação, Escola de Educação Física, Fisioterapia e Terapia Ocupacional, Universidade Federal de Minas Gerais, Belo Horizonte, MG, Brasil
\end{abstract}

\begin{abstract}
Resumo: $O$ estudo teve como objetivo observar o processo de ensino-aprendizagem-treinamento no futsal e analisar como o método de ensino aplicado influencia o conhecimento tático processual. A amostra foi composta por 15 jogadores de duas diferentes equipes $(n=30)$. As equipes disputavam competições da categoria sub-09. Houve o registro de 18 sessões de treinos por meio de filmagens. O método global propiciou melhoras no conhecimento tático processual no parâmetro oferecer e orientar-se e no reconhecer espaços. Com o método analítico houve melhoras apenas no parâmetro oferecer e orientar-se. Os resultados apontam que o treinamento centrado na tomada de decisão, no parâmetro tático, como indicativos para o desenvolvimento de jogadores capazes de ações autônomas inteligentes e criativas.
\end{abstract}

Palavras-chave: Cognição e Ação. Métodos de Ensino. Jogos Esportivos Coletivos.

The influence of teaching-learning-training methods onprocedural tactical knowledge in futsal

Abstract: The purpose of the present study was to observe the teaching-learning-training processes in futsal, and to asset how different methods applied influence on the acquisition of procedural tactical knowledge. The sample was composed by players aged 9 years from two different teams (15 players in each team, $n=30$ ). 18 training sessions of each team were filmed and analyzed. Global Method produced improvements on tactical procedural knowledge concerning "offer and orientate yourself" and "identification of gaps" tactical parameters. By applying the Analytical Method there were only enhancements in the parameter "offer and orientate yourself". The results show that training methods centered on decision making and development of tactical abilities are indicated to better promote the development of players capable of intelligent and creative actions.

Keywords: Cognition and Action. Teaching Methods. Team Ball Sports.

\section{Introdução}

No contexto dos Jogos Esportivos Coletivos (JEC) o conhecimento serve de apoio as decisões táticas dos atletas (GRECO, 2006). Os JEC se caracterizam pelo contexto ambiental em que as ações se desenvolvem com imprevisibilidade, aleatoriedade e variabilidade, em decorrência das múltiplas ações de conflito entre as equipes, mais as ações de colaboração no interior de cada equipe visando um mesmo objetivo tático (GARGANTA, 1998; MATIAS; GRECO, 2009). Para se ter sucesso taticamente é necessário que o atleta recorra aos processos cognitivos para formatação de decisões de forma autônoma (MESQUITA, 2005). Estas se expressam por meio da técnica, da ação motora que se realiza na situação como fruto de uma resposta inteligente e criativa sempre em interação com os companheiros, considerando as respostas dos adversários e o objetivo do jogo (MATIAS; GRECO, 2010). É precípuo ao atleta de uma modalidades dos JEC a qualificação em relação ao saber: "o que fazer", "quando fazer" e "como fazer" (GRECO; BENDA, 1998; OLIVEIRA et al., 2003; MORALES; GRECO, 2007).

Nas Ciências do Esporte, com aporte da Psicologia Cognitiva, há dois tipos de conhecimento tático: o declarativo e o processual (EYSENCK; KEANE, 1994; STERNBERG, 2008; MATIAS; GRECO, 2010). O declarativo permite que o atleta explique verbalmente a sua ação. Já o processual é automatizado, não consciente e permite que $o$ atleta efetue a ação de jogo propriamente dita, um gesto técnico mais apropriado de acordo com as diferentes tarefasproblemas inerentes a uma das modalidades dos JEC. Estes conhecimentos são utilizados por intermédio do pensamento convergente $e$ 
divergente (GRECO, 2006; STERNBERG, 2008). O convergente, relacionado com a inteligência tática, pode ser caracterizado pelos processos que possibilitam ao individuo escolher a alternativa adequada à situação de jogo (GRECO, 2006; MATIAS; GRECO, 2010). Já o divergente, relacionado com a criatividade tática, refere-se à formulação de idéias novas, adequadas e flexíveis, permitindo assim a efetuação de respostas em detrimento às diversas situações de jogo (GRECO, 2006; GIACOMINI; GRECO, 2008; BRITO; VANZIN; ULBRICHT, 2009; MATIAS; GRECO, 2010).

Em suma, os JEC se caracterizam pela sucessão constante de situações de jogo, nas quais 0 participante deve resolver problemas mediante inúmeras tomadas de decisões, decisões estas que envolvem um conteúdo tático e implicam em relacionar processos cognitivos com processos motores. Assim, quando um atleta realiza uma técnica específica da modalidade, por exemplo, um passe no futsal, ele toma uma decisão tática escolhendo esta ação motora como a mais adequada na resolução de uma situação específica de jogo. Logo, por meio da interação do conhecimento tático declarativo e processual são formuladas e apresentadas as resoluções inerentes as características e peculiaridades dos cenários do jogo ( $\underline{\text { GRECO}}, 2006$; $\underline{\text { MATIAS; }}$ GRECO, 2010).

A estruturação das atividades e a distribuição de conteúdos possuem um valor essencial no processo de ensino-aprendizagem-treinamento (E-A-T) dos JEC, uma vez que as atividades planificadas são primordiais para 0 desenvolvimento positivo do rendimento dos jogadores nos diferentes níveis de expressão da sua performance (SAAD, 2002). De tal modo, é importante investigar os métodos de ensino que estão sendo aplicados (nos clubes e nas escolas) e relacioná-los com o saber científico presente na literatura.

Por isto, este estudo teve as sessões de treino registradas (filmadas). Posteriormente foi possível a categorização dos conteúdos e das tarefas das sessões de treino. Após a categorização dos treinos analisou-se o método de ensino aplicado. A seguir foi possível apurar os efeitos do método aplicado no desenvolvimento do conhecimento tático processual.

Este estudo teve como objetivo a observação e a descrição dos métodos de ensino- apredizagem-treinamento empregados no escalão sub-09 do futsal. A partir disto foi investigado 0 efeito dos métodos identificados no conhecimento tático processual.

\section{Amostra}

\section{Métodos}

Participaram deste estudo trinta $(n=30)$ alunos do sexo masculino da modalidade esportiva coletiva Futsal da categoria Sub-09, idade entre 07 a 09 anos. A amostra apresentou a seguinte composição: grupo com treinamentos efetuados com base no método analítico (MA) foi composto por 15 jogadores (média de idade: 8,2 anos); grupo com treinamentos efetuados com base no método global (MG) teve 15 jogadores (média de idade: 8,7 anos).

Este estudo foi aprovado pelo Comitê de Ética em Pesquisa da Universidade Federal de Minas Gerais (processo $n^{\circ}:$ 251/04) e, por conseguinte respeitou as normas do Conselho Nacional de Saúde.

\section{Instrumento}

Aplicou-se o teste KORA (Avaliação Orientada através do Conceito dos Peritos), validado na Universidade de Heidelberg (MEMMERT, 2002), na Alemanha, para avaliar o conhecimento tático processual nos parâmetros "Oferecer-se e Orientar-se" (OO) e "Reconhecer Espaços" (RE), definidos respectivamente como "a qualidade do atleta de, a todo o instante, obter uma posição ótima para receber a bola" e "a qualidade necessária ao atleta para que ele perceba as possibilidades de se chegar ao gol" (KRÖGER; ROTH, 2002, p.32). No parâmetro tático $\mathrm{OO}$ avalia-se o comportamento do jogador SEM BOLA, já no RE o comportamento COM $A$ POSSE DA BOLA.

O teste KORA tem sido aplicado em pesquisas produzidas no Brasil, particularmente no Centro de Estudos de Cognição e Ação (CECA), na UFMG, entre elas destacam-se: Morales (2007), Giacomini (2007), Vilhena (2007), Morales; Greco (2007), Giacomini; Greco (2008), Lima (2008), Vilhena; Greco (2009), Greco, Memmert e Morales (2010), Pinho et al. (2010), Giacomini et al. (2011) e Lima, Matias e Greco (2012).

No teste OO (Figura 1) os atletas divididos em dois grupos de três jogadores se enfrentam em um espaço de 9x9 metros, de acordo com o protocolo de Memmert (2002). Os grupos são 
identificados com coletes de cores diferentes e os

jogadores são numerados de 01 a 03.

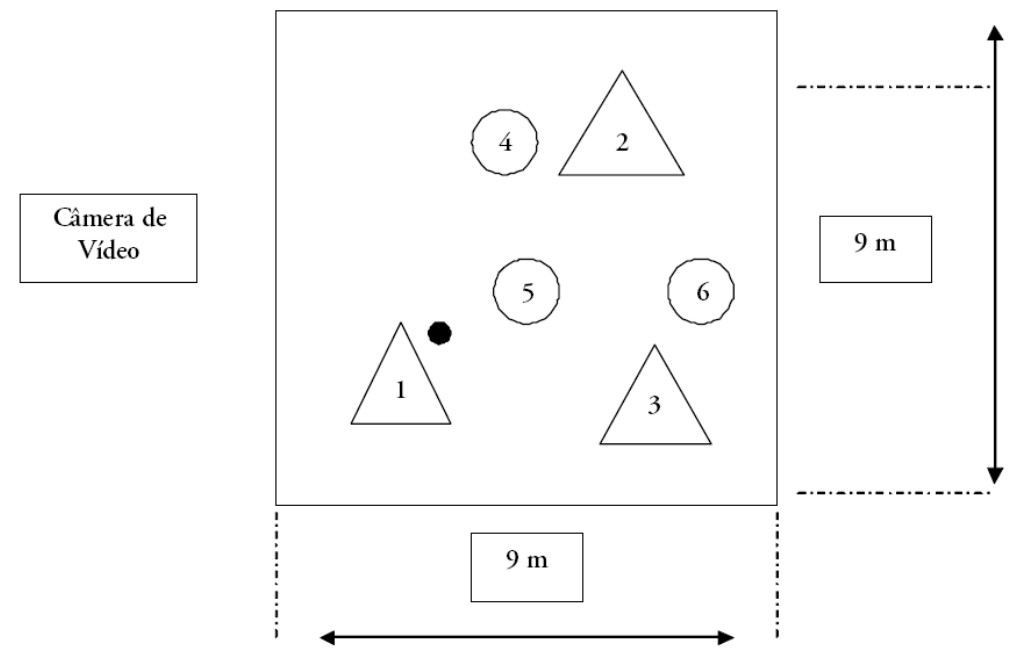

Figura 1. Protocolo de avaliação do conhecimento tático: oferecer-se e orientar-se

Os atacantes trocam passes entre si, com os pés, buscando manter a posse de bola, conforme estabelecido no protocolo de Memmert (2002), já os defensores possuem a função de interceptar estes passes. A movimentação é livre dentro da área demarcada. Toda vez que a bola é recuperada pelos defensores, ou sai da área determinada, o jogo é interrompido e reiniciado pela equipe de ataque, no centro do quadrado. Ao final de três minutos procede-se a troca de funções entre os grupos. Ressalta-se que os defensores não podem retirar a bola dos atacantes por meio de desarmes, podem somente interceptar os passes, com a manutenção de aproximadamente 1 metro de distância do jogador em posse da bola. No momento do domínio, da recepção de bola, o defensor pode se aproximar e pressionar, sem retirar a bola, mas logo que esta é dominada ele deve se afastar um metro.

No teste RE (Figura 2) os atletas são divididos em três setores, em um espaço de $7 \times 8$ metros e realizam um jogo por um período de dois minutos, de acordo com o protocolo de Memmert (2002).

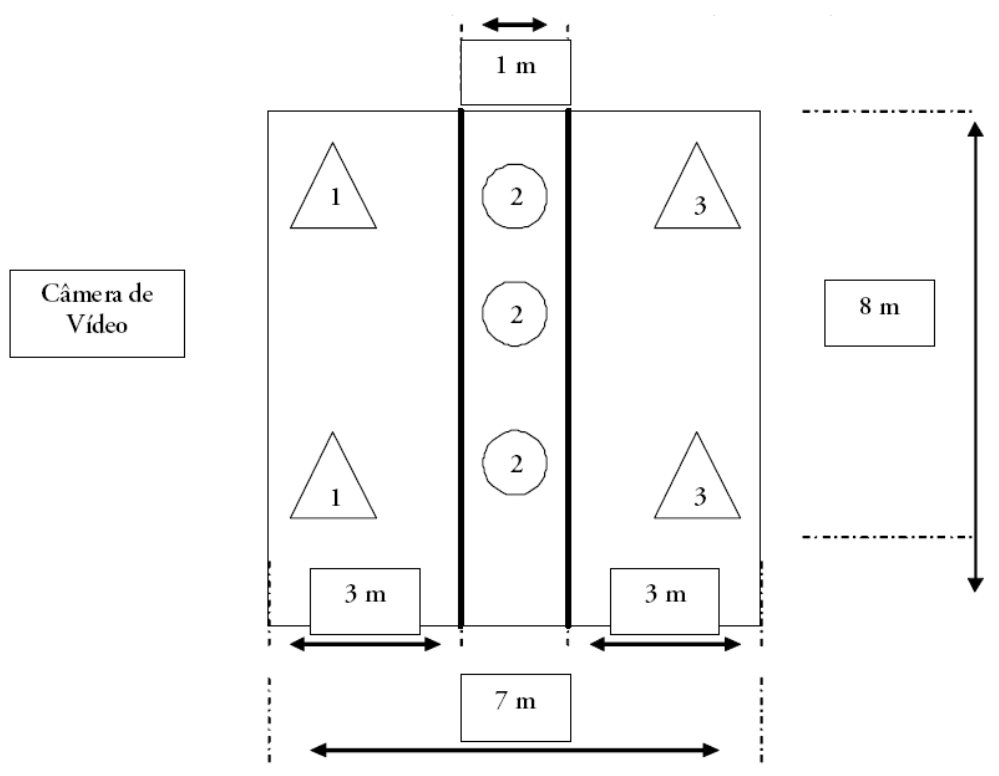

Figura 2. Protocolo de avaliação do conhecimento tático: reconhecer espaços.

Os atletas dos setores 1 e 3 fazem parte da mesma equipe (atacantes) e devem trocar passes dentro do próprio setor, com o objetivo de passar a bola para o setor 3 , por meio do uso dos pés e 
pela percepção de espaço livre no setor 2 . Os atletas do setor 2 (defensores) procuram interceptar os passes destinados ao setor 3. Os atacantes não podem conduzir a bola, somente fintar com o corpo ou passar a bola para o companheiro do mesmo setor. No momento mais propício efetua-se o passe para o colega do outro setor.

Os passes realizados entre os setores 1 e 3 não podem ultrapassar uma altura máxima, determinada pela altura dos ombros dos defensores, sendo invalidadas as bolas que ultrapassarem esta altura. Sempre que houver a interceptação do passe entre os atletas dos setores 1 e 3 , pelo grupo do setor 2 , a bola será entregue para o grupo contrário ao que originou 0 passe interceptado. É importante ressaltar que os atacantes dentro de seu setor podem se deslocar livremente trocando de posição entre si sem, no entanto, trocar de setor, isto é "ir para o outro lado". Já os defensores podem deslocar-se livremente trocando de posição entre si, mas não podem sair espaço defensivo delimitado.

Quadro 1. Gabarito: pontuação do teste KORA Oferecer-se e Orientar-se (convergente)

\begin{tabular}{|c|c|c|c|}
\hline $\begin{array}{l}\text { Qualidade da solução: } \\
\text { se oferecer se orientar, procurar a } \\
\text { posição adequada para receber a bola. }\end{array}$ & $\begin{array}{c}\text { Nível de definição da } \\
\text { situação }\end{array}$ & Pontos & Exemplo \\
\hline $\begin{array}{c}\text { Ótimo } \\
\text { Sempre Livre }\end{array}$ & DIFÍCIL & 10 & $\begin{array}{l}\text { O atleta tem, apesar de estar em uma situação difícil, } \\
\text { procurado sempre uma boa posição para dar a quem tem } \\
\text { a bola opção de passe. }\end{array}$ \\
\hline $\begin{array}{l}\text { Ótimo } \\
\text { Sempre Livre }\end{array}$ & FÁCIL & 9 & $\begin{array}{l}\text { O atleta tem, procurado sempre a posição ótima e } \\
\text { oferecido ao colega a possibilidade de passe. No entanto, } \\
\text { a situação não era tão difícil. }\end{array}$ \\
\hline $\begin{array}{c}\text { Muito bom } \\
\text { Quase Sempre }\end{array}$ & DIFICIL & 8 & $\begin{array}{l}\text { O atleta tem apesar de estar em uma situação difícil } \\
\text { procurado quase sempre achar a posição ótima para que } \\
\text { seu colega em posse de bola efetue o passe. }\end{array}$ \\
\hline $\begin{array}{c}\text { Muito bom } \\
\text { Quase Sempre }\end{array}$ & FÁCIL & 7 & $\begin{array}{l}\text { O atleta tem procurado quase sempre a posição ótima } \\
\text { para que o colega em posse de bola tenha a opção de } \\
\text { passe, no entanto a situação não era muito difícil. }\end{array}$ \\
\hline $\begin{array}{c}\text { Bom } \\
\text { Freqüentemente }\end{array}$ & DIFÍCIL & 6 & $\begin{array}{l}\text { O atleta apesar de estar em uma posição difícil tem } \\
\text { procurado freqüentemente uma posição ótima para dar a } \\
\text { possibilidade de passe. }\end{array}$ \\
\hline $\begin{array}{l}\text { Suficiente } \\
\text { Alternadamente }\end{array}$ & FÁCIL & 5 & $\begin{array}{l}\text { O atleta tem de forma irregular procurado a posição ótima } \\
\text { e oferecido ao portador da bola quase sempre a } \\
\text { possibilidade de passe. No entanto a situação não era } \\
\text { difícil. }\end{array}$ \\
\hline $\begin{array}{c}\text { Pobre } \\
\text { Quase Nunca }\end{array}$ & DIFÍCIL & 4 & $\begin{array}{l}\text { O atleta não tem quase nunca procurado a posição ótima } \\
\text { de forma a oferecer ao portador da bola a opção de } \\
\text { passe, no entanto a situaçãao de jogo era difícil. }\end{array}$ \\
\hline $\begin{array}{c}\text { Pobre } \\
\text { Quase Nunca }\end{array}$ & FÁCIL & 3 & $\begin{array}{l}\text { O atleta apesar de estar em uma situação fácil não tem } \\
\text { procurado quase nunca uma posição ótima para oferecer } \\
\text { ao colega (portador da bola) a opção de passe. }\end{array}$ \\
\hline $\begin{array}{l}\text { Insuficiente } \\
\text { Nunca }\end{array}$ & DIFÍCIL & 2 & $\begin{array}{l}\text { O atleta não tem procurado quase nunca a posição ótima } \\
\text { para oferecer ao colega (portador da bola) a opção de } \\
\text { passe. No entanto, era uma situação difícil. }\end{array}$ \\
\hline $\begin{array}{l}\text { Insuficiente } \\
\text { Nunca }\end{array}$ & FACIL & 1 & $\begin{array}{l}\text { O atleta apesar de estar em uma situação fácil não tem } \\
\text { procurado nunca uma ótima posição para oferecer ao } \\
\text { colega a opção de passe. }\end{array}$ \\
\hline
\end{tabular}

Ao fim dos registros por meio das filmagens efetua-se a avaliação do conhecimento processual no parâmetro $\mathrm{OO}$ e no RE, referente ao pensamento convergente e divergente. Três peritos no teste KORA analisam as ações realizadas COM A POSSE DE BOLA e SEM A POSSE DE BOLA, respectivamente, de acordo com os critérios estabelecidos por Memmert
(2002) em uma escala de pontuação (gabarito) que varia entre 1 a 10 pontos (Quadro 1, 2, 3 e 4). Ressalta-se que tais peritos participarão de um curso específico que aborda o KORA e ao final de uma avaliação foram aprovados como peritos. Os peritos compreendem de forma objetiva os critérios do teste KORA. O processo de validação e aplicação tem em sua composição a formação de peritos no KORA. 
Quadro 2. Gabarito: pontuação do teste KORA Oferecer-se e Orientar-se (divergente)

\begin{tabular}{|c|c|c|c|}
\hline $\begin{array}{l}\text { Originalidade da Solução na } \\
\text { Situação de jogo: uso do } \\
\text { espaço ou passe }\end{array}$ & $\begin{array}{l}\text { Flexibilidade nas } \\
\text { soluções das } \\
\text { situaçôes de jogo. }\end{array}$ & Pontos & Exemplo \\
\hline $\begin{array}{l}\text { Amplo acima da media } \\
\text { (muito original) }\end{array}$ & $\begin{array}{l}\text { Duas ou mais } \\
\text { (ações originais) }\end{array}$ & 10 & $\begin{array}{l}\text { O atleta demonstra diferentes soluções originais, pouco comuns ou } \\
\text { pouco conhecidas / esperadas várias vezes para resolver a } \\
\text { situação. As procuras temporais de ótimas posições foram sempre } \\
\text { (completamente) excelentes. }\end{array}$ \\
\hline $\begin{array}{c}\text { Amplo acima da média } \\
\text { (original) }\end{array}$ & $\begin{array}{l}\text { Duas ou mais } \\
\text { (ações originais) }\end{array}$ & 9 & $\begin{array}{l}\text { O atleta demonstra diferentes soluções originais (fora do comum), } \\
\text { ou pouco conhecidas. As procuras temporais de ótimas posições } \\
\text { foram sempre muito boas. }\end{array}$ \\
\hline $\begin{array}{l}\text { Acima da média } \\
\text { (quase sempre) }\end{array}$ & $\begin{array}{l}\text { Duas ações } \\
\text { (originais, raridade que } \\
\text { não aparecem de forma } \\
\text { pouco freqüente) }\end{array}$ & 8 & $\begin{array}{l}\text { O atleta demonstra duas diferentes soluções originais (fora do } \\
\text { comum), ou pouco conhecidas. As procuras temporais de ótimas } \\
\text { posições foram sempre boas. }\end{array}$ \\
\hline $\begin{array}{l}\text { Bom, na média } \\
\text { (algumas vezes) }\end{array}$ & $\begin{array}{l}\text { Duas ações novas (que } \\
\text { aparecem de forma } \\
\text { pouco freqüente) }\end{array}$ & 7 & $\begin{array}{l}\text { O atleta demonstra duas diferentes soluções que não foram } \\
\text { originais (fora do comum), mas que aparecem de forma esporádica. } \\
\text { As procuras temporais de ótimas posições foram sempre } \\
\text { surpresas. }\end{array}$ \\
\hline $\begin{array}{c}\text { Na média } \\
\text { (ainda faz coisas novas) }\end{array}$ & $\begin{array}{l}\text { Duas ações } \\
\text { (pouco freqüentes) }\end{array}$ & 6 & $\begin{array}{l}\text { O atleta demonstra duas diferentes soluções que não foram } \\
\text { originais, mas que aparecem de forma esporádica. As procuras } \\
\text { temporais de ótimas posições foram sempre surpresas. }\end{array}$ \\
\hline $\begin{array}{l}\text { Suficiente, ainda } \\
\text { (consegue coisas novas) }\end{array}$ & $\begin{array}{c}\text { Uma } \\
\text { (Ação pouco freqüente) }\end{array}$ & 5 & $\begin{array}{l}\text { O atleta demonstra uma diferente solução que não são dentro do } \\
\text { repertório padrão, mas que já apareceram. As procuras temporais } \\
\text { de ótimas posições tiveram sim novidade. }\end{array}$ \\
\hline $\begin{array}{l}\text { Pobre, próximo da média } \\
\text { (com poucas coisas novas) }\end{array}$ & $\begin{array}{c}\text { Uma } \\
\text { (Ação pouco freqüente) }\end{array}$ & 4 & $\begin{array}{l}\text { O atleta demonstra uma diferente solução que não são dentro do } \\
\text { repertório padrão, mas que aparecem freqüentemente. As procuras } \\
\text { temporais de ótimas posições tiveram sim ainda uma novidade. }\end{array}$ \\
\hline $\begin{array}{l}\text { Pobre, abaixo da média } \\
\text { (próximo do padrão) }\end{array}$ & Nenhuma & 3 & $\begin{array}{l}\text { O atleta demonstra em regra gerais soluções, dentro do repertório } \\
\text { padrão, que aparecem freqüentemente. Ocasionalmente as } \\
\text { procuras temporais de ótimas posições tiveram um pouco de } \\
\text { novidade. }\end{array}$ \\
\hline $\begin{array}{c}\text { Insuficiente } \\
\text { (quase somente padrão) }\end{array}$ & Nenhuma & 2 & $\begin{array}{l}\text { O atleta demonstra quase somente soluções dentro do repertório } \\
\text { padrão, que aparecem sempre. Muito ocasionalmente as procuras } \\
\text { temporais de ótimas posições tiveram um pouco de novidade. }\end{array}$ \\
\hline $\begin{array}{l}\text { Muito Insuficiente } \\
\text { (Somente padrão) }\end{array}$ & Nenhuma & 1 & $\begin{array}{l}\text { O atleta demonstra somente soluções padrões, que aparecem } \\
\text { sempre. As procuras temporais de ótimas posições não tiveram } \\
\text { novidade. }\end{array}$ \\
\hline
\end{tabular}

Quadro 3. Gabarito: pontuação do teste KORA Reconhecer Espaços (convergente)

\begin{tabular}{|c|c|c|c|}
\hline $\begin{array}{c}\text { Qualidade da solução } \\
\text { utilização } \\
\text { dos espaços ou passe }\end{array}$ & $\begin{array}{l}\text { Nível de dificuldade } \\
\text { da situação }\end{array}$ & Pontos & Exemplo \\
\hline $\begin{array}{l}\text { Ótimo } \\
\text { Sempre Livre }\end{array}$ & Difícil & 10 & $\begin{array}{l}\text { O atleta enfrenta situações difíceis sempre utilizando o espaço de } \\
\text { forma ótima ou passando a bola para um colega melhor } \\
\text { posicionado. }\end{array}$ \\
\hline $\begin{array}{l}\text { Ótimo } \\
\text { Sempre Livre }\end{array}$ & Fácil & 9 & $\begin{array}{l}\text { O atleta enfrenta somente uma situação de tensão e utiliza o } \\
\text { espaço de forma ótima. Nas outras situações a dificuldade é } \\
\text { média. }\end{array}$ \\
\hline $\begin{array}{c}\text { Muito Bom } \\
\text { Quase Sempre }\end{array}$ & Difícil & 8 & $\begin{array}{l}\text { O atleta utiliza os espaços sempre de maneira adequada, enfrenta } \\
\text { apenas uma situação de grande dificuldade. }\end{array}$ \\
\hline $\begin{array}{l}\text { Muito Bom } \\
\text { Quase Sempre }\end{array}$ & Fácil & 7 & $\begin{array}{l}\text { O atleta utiliza quase sempre o espaço de maneira ótima, mas } \\
\text { enfrenta um defensor mais fraco quando aparecem as situações } \\
\text { de jogo. }\end{array}$ \\
\hline $\begin{array}{l}\text { Bom } \\
\text { Freqüentemente }\end{array}$ & Difícil & 6 & $\begin{array}{l}\text { O atleta alterna momentos bons e ruins em seu jogo. Enfrentou } \\
\text { situações fáceis e difíceis alternadamente.. }\end{array}$ \\
\hline $\begin{array}{c}\text { Suficiente } \\
\text { Alternadamente }\end{array}$ & Fácil & 5 & $\begin{array}{l}\text { O atleta apresenta várias decisões críticas, mas nenhuma errada. } \\
\text { As situações eram de dificuldade média. }\end{array}$ \\
\hline $\begin{array}{c}\text { Pobre } \\
\text { Quase nunca }\end{array}$ & Difícil & 4 & $\begin{array}{l}\text { O atleta cometeu alguns erros graves em situações simples, no } \\
\text { entanto utiliza os espaços de forma adequada. }\end{array}$ \\
\hline $\begin{array}{c}\text { Pobre } \\
\text { Quase nunca }\end{array}$ & Fácil & 3 & $\begin{array}{l}\text { O atleta apresenta várias decisões erradas, mas não cometeu } \\
\text { erros graves em situações difíceis. }\end{array}$ \\
\hline $\begin{array}{l}\text { Insuficiente } \\
\text { Nunca }\end{array}$ & Difícil & 2 & $\begin{array}{l}\text { O atleta apresentou várias decisões criticas em situações que } \\
\text { foram consideradas de dificuldade média. }\end{array}$ \\
\hline $\begin{array}{l}\text { Insuficiente } \\
\text { Nunca }\end{array}$ & Fácil & 1 & O atleta cometeu muitos e alternados erros em situações simples. \\
\hline
\end{tabular}


Quadro 4. Gabarito: pontuação do teste KORA Reconhecer Espaços (divergente)

\begin{tabular}{|c|c|c|c|}
\hline $\begin{array}{l}\text { Originalidade da Solução } \\
\text { na situação de jogo } \\
\text { uso do espaço ou passe }\end{array}$ & $\begin{array}{l}\text { Flexibilidade nas } \\
\text { soluções das } \\
\text { situações de jogo }\end{array}$ & Pontos & Exemplo \\
\hline $\begin{array}{l}\text { Amplo acima da media } \\
\text { (muito original) }\end{array}$ & $\begin{array}{l}\text { Duas ou mais } \\
\text { (ações originais) }\end{array}$ & 10 & $\begin{array}{l}\text { O atleta demonstra diferentes soluções originais, pouco comuns } \\
\text { ou pouco conhecidas (esperadas varias vezes). A descoberta de } \\
\text { espaços ou a realização de passes foram sempre } \\
\text { (completamente) excelentes. }\end{array}$ \\
\hline $\begin{array}{l}\text { Amplo acima da média } \\
\text { (original) }\end{array}$ & $\begin{array}{l}\text { Duas ou mais } \\
\text { (ações originais) }\end{array}$ & 9 & $\begin{array}{l}\text { O atleta demonstra diferentes alternativas originais (fora do } \\
\text { comum de solução). A descoberta de espaços ou a realização de } \\
\text { passes foram excelentes. }\end{array}$ \\
\hline $\begin{array}{l}\text { Muito bom } \\
\text { (quase sempre) }\end{array}$ & $\begin{array}{c}\text { Duas } \\
\text { (ações originais / que } \\
\text { aparecem de forma } \\
\text { pouco freqüente) }\end{array}$ & 8 & $\begin{array}{l}\text { O atleta demonstra diferentes alternativas originais (fora do } \\
\text { comum de solução). A descoberta de espaços, ou de passes, foi } \\
\text { pouco freqüente. }\end{array}$ \\
\hline $\begin{array}{l}\text { Bom, na média } \\
\text { (algumas vezes) }\end{array}$ & $\begin{array}{l}\text { Duas (ações que } \\
\text { aparecem de forma } \\
\text { pouco freqüente) }\end{array}$ & 7 & $\begin{array}{l}\text { O atleta demonstra duas alternativas de soluções diferentes, que } \\
\text { não foram pouco comuns, mas que aparecem na prática com } \\
\text { pouca freqüência. As descobertas dos espaços e dos passes } \\
\text { foram sempre cheias de muita surpresa. }\end{array}$ \\
\hline $\begin{array}{c}\text { Na média } \\
\text { (ainda faz coisas novas) }\end{array}$ & $\begin{array}{l}\text { Duas } \\
\text { (ações pouco } \\
\text { freqüentes, novas) }\end{array}$ & 6 & $\begin{array}{l}\text { O atleta demonstra duas alternativas de soluções diferentes, que } \\
\text { não foram pouco comuns, mas que aparecem na prática com } \\
\text { pouca freqüência. As descobertas dos espaços e de passes foram } \\
\text { sempre surpresas. }\end{array}$ \\
\hline $\begin{array}{l}\text { Suficiente, ainda } \\
\text { (consegue coisas novas) }\end{array}$ & $\begin{array}{c}\text { Uma } \\
\text { (Ação pouco freqüente) }\end{array}$ & 5 & $\begin{array}{l}\text { O atleta demonstra duas alternativas de solução diferentes, as } \\
\text { mesmas não são do tipo padrão, mais que apareceram já no jogo. } \\
\text { As descobertas dos espaços e dos passes foram com novidades. }\end{array}$ \\
\hline $\begin{array}{l}\text { Pobre, próximo da média } \\
\text { (com poucas coisas novas) }\end{array}$ & $\begin{array}{c}\text { Uma } \\
\text { (Ação pouco freqüente) }\end{array}$ & 4 & $\begin{array}{l}\text { O atleta demonstra duas alternativas de solução diferentes, as } \\
\text { mesmas não são do tipo padrão, mais que aparecem } \\
\text { freqüentemente no jogo. As descobertas dos espaços e dos } \\
\text { passes foram com novidades. }\end{array}$ \\
\hline $\begin{array}{c}\text { Pobre } \\
\text { (próximo do padrão) }\end{array}$ & Nenhuma & 3 & $\begin{array}{l}\text { O atleta tem apresentado geralmente soluções padrão, as que já } \\
\text { foram oferecidas. As descobertas dos espaços e dos passes } \\
\text { foram com um pouco de novidade ainda. }\end{array}$ \\
\hline $\begin{array}{c}\text { Insuficiente } \\
\text { (quase somente padrão) }\end{array}$ & Nenhuma & 2 & $\begin{array}{l}\text { O atleta tem apresentado quase sempre soluções padrão, as que } \\
\text { já foram oferecidas. As descobertas dos espaços e dos passes } \\
\text { foram com pouca novidade. }\end{array}$ \\
\hline $\begin{array}{l}\text { Muito Insuficiente } \\
\text { (Somente padrão) }\end{array}$ & Nenhuma & 1 & $\begin{array}{l}\text { O atleta tem apresentado somente soluções padrão, as que já } \\
\text { foram oferecidas. As descobertas dos espaços e dos passes } \\
\text { nunca foram novidade. }\end{array}$ \\
\hline
\end{tabular}

Foram filmadas, em cada uma das equipes deste estudo, 18 sessões de treino (cerca de seis semanas) e posteriormente realizada a observação sistemática e direta dos treinos (categorização) mediante 0 protocolo de classificação das sessões de treinamento elaborada por Saad (2002). Este protocolo foi aplicado em outros estudos, tais como: Mendes (2006), Collet et al. (2007), Morales (2007), Vilhena (2007), Morales; Greco (2007), Lima (2008), Morales et al. (2009), Vilhena; Greco (2009) e Lima, Matias e Greco (2012). Três professores de Educação Física, com mais de 10 anos de experiência como treinadores de futsal, efetuaram a categorização dos treinos e assim foi possível confirmar a aplicação do MA e do MG em cada uma das equipes.

\section{Procedimentos}

O teste KORA OO e RE foi aplicado em dois momentos distintos: anteriormente a efetuação das dezoito sessões de treinamento e ao fim deste conjunto de sessões (Pré-Teste e PósTeste). Cada sessão teve duração média de 90 minutos. Logo, realizou-se uma avaliação específica do conhecimento tático processual (OO e RE) de cada equipe.

As dezoito sessões de treinamento foram filmadas, entre o Pré-Teste e Pós-Teste, e analisadas posteriormente, para conferência e confirmação da aplicação do método de ensino no processo de ensino-aprendizagem-treinamento aplicado pelos treinadores responsáveis por cada uma das equipes.

A aplicação do método analítico e global confirmou-se em cada uma das equipes avaliadas 
por meio da observação das filmagens dos treinos realizadas por três professores de Educação Física, que são treinadores de futsal (MA: 1063 minutos de treino ao todo; MG: 1618 minutos de treino ao todo). Para averiguação destes métodos nos treinos usou-se o protocolo de Saad (2002) que é composto por parâmetros com a seguinte definição:

a) Segmento de treino - composto por: conversa com o treinador, treino técnico, treino tático, treino tático-técnico e jogo.

b) Duração - tempo gasto para a realização de cada atividade;

c) Condições da tarefa - classificadas em: Fundamento Individual: execução de fundamentos técnicos isolados (voltada para o desenvolvimento técnico); Combinação de Fundamentos: passe, condução, recepção, drible e chute (voltada para o desenvolvimento técnico); Complexo de Jogo I: situações de jogo com enfoque tático, realizadas por intermédio da utilização das estruturas funcionais: $1 \times 1 ; 1 \times 1+1$, $2 \times 1,2 \times 2$; etc. (voltada para o desenvolvimento tático-técnico); Complexo de Jogo II: situações de jogo com enfoque tático, representadas por pequenos jogos com ênfase em situações de jogo: contra-ataque, retorno defensivo, etc. (voltada para o desenvolvimento tático-técnico); Jogo Formal: atividade de competição governada por regras estabelecidas, onde os resultados são decididos pelas habilidades e estratégias (voltado para o desenvolvimento técnico).

d) Exercícios realizados nas sessões de treino classificados como: Fundamento individual sem oposição (adversário); Combinação de fundamento sem oposição; Combinação de fundamento com oposição; Situação de jogo com oposição simplificada; Situação de jogo semelhante.

Três peritos no teste KORA avaliaram individualmente, e em momentos diferentes, os pré-testes e os pós-testes das duas equipes. Além disto, três professores/treinadores de futsal classificaram as atividades abordadas em cada um dos métodos de E-A-T aplicados em cada uma das equipes. Esta pesquisa seguiu 0 delineamento exposto na Figura 3.

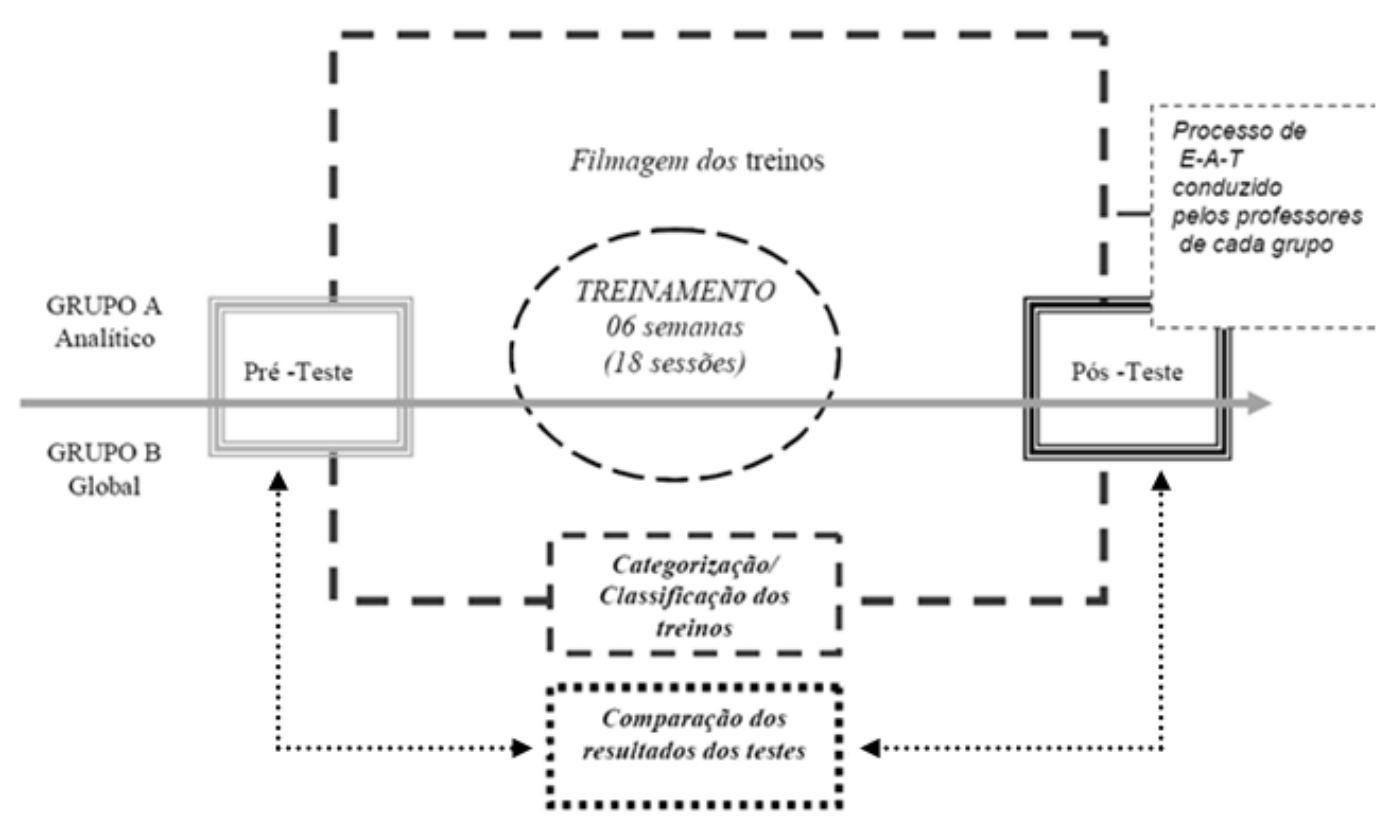

Figura 3. Delineamento Experimental.

\section{Tratamento Estatístico}

O procedimento estatístico usado na apuração das diferenças significativas entre os escores do Pré e Pós-teste foi o teste não-paramétrico de Wilcoxon, pois permite a comparação entre dois grupos pareados. Foi também empregado o teste de Wilcoxon uma vez que não faz sentido calcular a média ou o desvio-padrão para os valores ordinais, os testes paramétricos normalmente não são apropriados. Além disto, os grupos são compostos por amostras pequenas e uma distribuição não normal, mais um indicativo para o emprego técnicas não paramétricas (PAGANO;
GAUVREAU, 2006). O nível de significância adotado foi de $p<0,05$. O cálculo do coeficiente de Alfa de Conbrach determinou a consistência interna na avaliação dos peritos do KORA, obtendo valores de 0,92 para o grupo MG e de 0,90 para o grupo MA, acima dos limites definidos na literatura (THOMAS; NELSON, 2002). Os dados obtidos na observação sistemática dos treinos foram analisados por meio da estatística descritiva. O software empregado na análise dos dados foi o SPSS (versão 11.0). 


\section{Apresentação e Discussão dos Resultados}

A distribuição do segmento dos treinamentos das equipes MA e MG (Gráfico 1) permite afirmar que a equipe $M G$, com uma proposta de treinamento predominantemente global, destinou a maior parte do tempo ao treinamento táticotécnico e ao jogo (32\% e $45 \%$, respectivamente) e nenhum tempo ao treinamento isolado da técnica.

Além disto, dedicou parte do tempo exclusivamente para o treino da tática (18\%). A equipe MA, com uma proposta de treinamento baseada no método analítico, destinou maior parte da carga horária ao treino específico da técnica $(47 \%)$ e nenhum tempo exclusivo ao treinamento tático.

Gráfico 1. Comparação da distribuição dos segmentos dos treinamentos das equipes MA e MG.

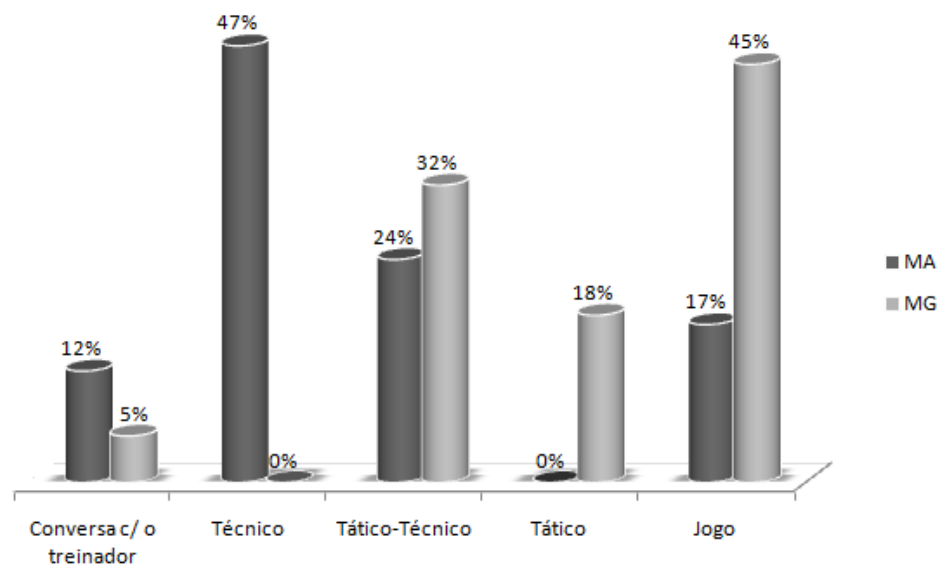

A partir da distribuição das tarefas (Gráfico 2) observa-se que a equipe MA usou maior parte do seu tempo com o parâmetro combinação de fundamentos (53\%). O treinamento desta equipe teve sua ênfase na progressão complexa no ensino dos elementos da técnica individual em suas tarefas, se confirma assim a visão de aplicação do método analítico. Já a equipe $M G$ teve o seu treino voltado principalmente ao jogo formal (48\%). Não se observa nesta equipe um tempo voltado ao treino de fundamentos individuais, bem como não há também uma progressão complexa da aprendizagem, se caracteriza assim a aplicação do método global.

Gráfico 2. Comparação da distribuição das condições das tarefas realizadas nos treinamentos das equipes MA e MG.

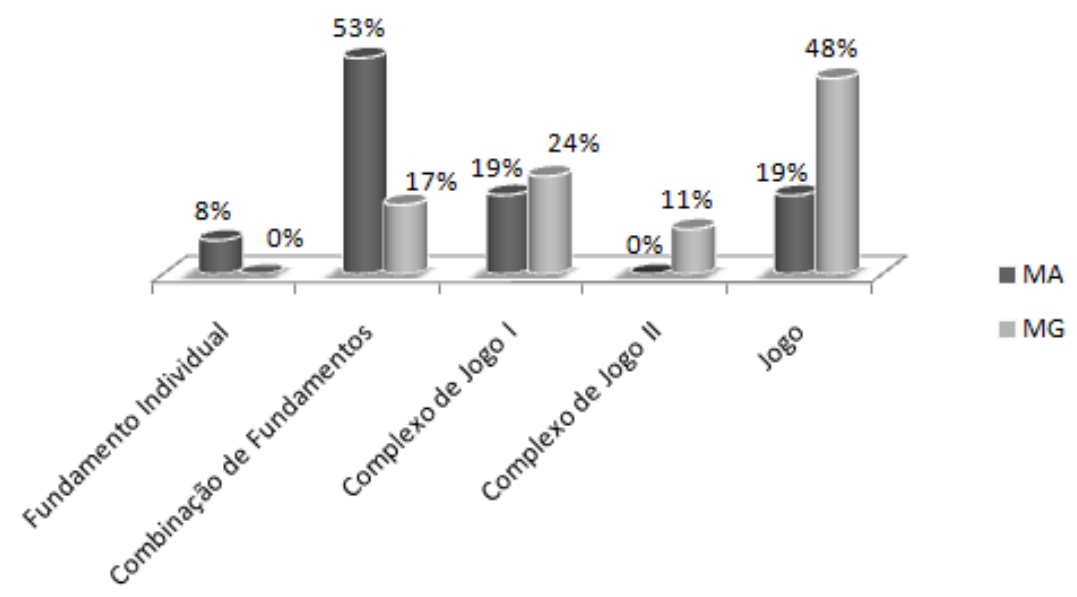

A equipe $M A$ e a $M G$ apresentam formas de exercícios diferentes nas sessões de treinamento (Gráfico 3). A equipe MA dedicou maior parte do tempo total aos exercícios com combinação de fundamentos sem oposição $(46 \%)$, se revela assim uma grande preocupação com 0 treino direcionado a repetição e mecanização do gesto técnico; outro parâmetro encontrado nas sessões de treino da equipe MA foi o treino de fundamento da técnica individual sem oposição (31\%), seguido de situação de jogo com oposição simplificada (12\%). Estes dados revelam que além da prevalência do ensino direcionado a automatização do gesto técnico, não houve nenhum espaço de tempo ao treinamento de exercícios com combinação de fundamentos com 
oposição. Assim, a ênfase nas sessões de treinos foi concentrada na realização de exercícios repetitivos, analíticos, sem apresentar uma contextualização como o que se encontra no jogo propriamente dito. Já a equipe MG dedicou maior parte do tempo total de seus exercícios a situações de jogo com oposição simplificada (49\%), seguido de combinação de fundamentos com oposição (34\%) e combinação de fundamento sem oposição (17\%). Desta forma observa-se que esta equipe direcionou suas atividades em tarefas que continham ingredientes do jogo. Isto, pois, contextualizou o movimento técnico no cerne do treinamento tático, assim tendo uma maior vivência em situações semelhantes ao jogo.

Gráfico 3. Comparação dos exercícios realizados nas sessões de treinamento das equipes MA e MG.

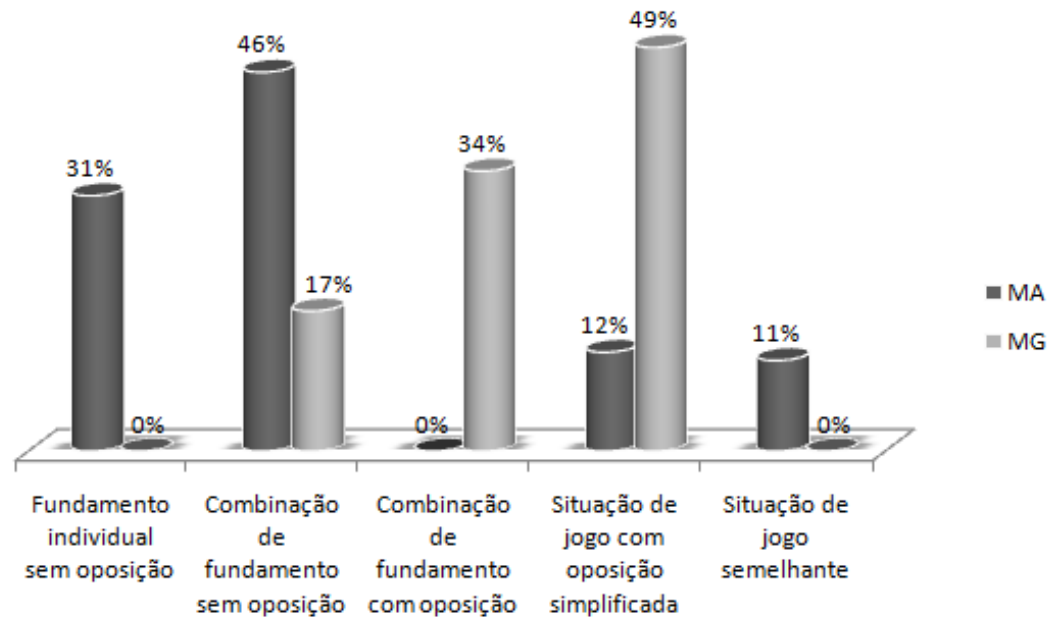

As evidências decorrentes da comparação de exercícios realizados nas sessões de treino, em interação com as demais, confirmam o emprego de métodos de E-A-T diferentes para cada grupo (STEFANELLO, 1999).

Assim, a equipe MA teve seu treino baseado no método analítico, um dos métodos tradicionais mais aplicados no processo de E-A-T ( $\underline{\text { GRECO }}$, 2001). O mesmo caracteriza-se pelas atividades voltadas para o aperfeiçoamento da técnica, sendo esta realizada normalmente de maneira desvinculada da situação real de jogo (FERREIRA; GALATTI; PAES, 2005; GRECO, 2001; TAVARES, 2002). Este método de ensino se deriva das concepções presentes na teoria associacionista, já que o método analítico se apóia na idéia de ensinar os conteúdos por partes. Assim, uma técnica motora é dividida em partes para em seguida, uni-las entre si, e após o domínio da técnica na sua forma total, se proceder ao ensino dos elementos táticos (GRECO, 2001).

O objetivo principal do método analítico é a aquisição e aperfeiçoamento das diferentes técnicas, ou seja, dos gestos esportivos. Caracteriza-se pela utilização da instrução direta, baseada na estruturação do ensino por meio de uma seqüência em série que leva o aluno, de forma progressiva, ao alcance da meta prevista. É um método centrado no professor, massivo e analítico (GIMÉNEZ, 2005). O método analítico contribui para gerar um jogo pouco criativo, com comportamentos estereotipados e com problemas em sua compreensão tática (OLIVEIRA; PAES, 2004).

O método global sugere a realização de seqüências simplificadas de jogo a partir de uma exigência real da modalidade (GREGO; BENDA, 1998). Neste princípio, tanto as questões táticas quanto as técnicas são aprendidas e vivenciadas por intermédio de jogos (FERREIRA; GALATTI; PAES, 2005).

A formatação deste método segue determinados princípios, entre eles ( $\underline{\mathrm{GRECO}}$; BENDA, 1998): a divisão dos jogos não deve abranger muitas partes; as formas prévias de jogo não podem ser mais difíceis que o jogo real; com jogos e pequenos grupos, realizados em pequenos espaços, os alunos aprendem de forma mais intensa. No conceito do método global os atletas ao jogar efetuam as tomadas de decisões considerando fatores como adversáriocompanheiro e o que fazer ao estar com a posse da bola ao mesmo tempo em que interagem com os imprevistos da interação inter e intra equipes. As habilidades são executadas em um contexto de jogo de forma aberta, propício ao desenvolvimento da compreensão do jogo. Assim, por intermédio da integração dos aspectos técnicos e táticos o jogador obtém a melhoria da 
performance de jogo (PINTO; SANTANA, 2005; GRACQA; MESQUITA, 2007).

Para a apresentação dos resultados derivados da análise do teste de conhecimento tático processual convergente/divergente KORA OO e $\mathrm{RE}$, no pré-teste e pós-teste, foi empregada a soma total de pontos obtidos pela equipe MA e MG e usou-se também a mediana. A mediana apurada foi relacionada com o gabarito do KORA (MEMMERT, 2002). Este gabarito possui uma escala crescente de 1 a $10 \mathrm{com}$ diferentes significados (GIACOMINI et al., 2011; LIMA; MATIAS; GRECO, 2012). Posteriormente foi empregado o teste não-paramétrico de Wilcoxon para verificar diferenças significativas entre os escores do pré e pós-testes das duas equipes.

$\mathrm{Na}$ Tabela 1 constam os valores apurados em relação ao parâmetro $\mathrm{OO}$ convergente (inteligência tática), referentes ao pré-teste e 0 pós-teste das duas equipes.

Tabela 1. Resultado do pré-teste e do pós-teste para conhecimento tático processual $\mathrm{OO}$ convergente (inteligência tática).

\begin{tabular}{lccccc}
\hline & \multicolumn{3}{c}{ Equipe MA } & \multicolumn{2}{c}{ Equipe MG } \\
& Pré-Teste & Pós-Teste & Pré-Teste & Pós-Teste \\
\hline Pontos & 138 & 178 & 236 & 265 \\
Mediana & 3 & 5 & 6 & & 7 \\
Valor $p$ & $0,018^{*}$ & & $0,034^{*}$ \\
\hline
\end{tabular}

$\mathrm{Na}$ equipe MA houve um aumento significativo $(p=0,018)$ no total de pontos obtidos do pré-teste (138) para o pós-teste (178). Além disso, a mediana apresentou um valor de 3 pontos no préteste. Já no pós-teste o valor da mediana foi de 5 pontos. Estes valores das medianas do pré-teste e do pós-teste, de acordo com o gabarito do KORA:OO convergente, significa, respectivamente, que os jogadores: "não tinham procurado quase nunca a posição ótima para oferecer aos colegas (portador da bola) a opção de passe. No entanto, era uma situação de jogo difícil". Após as 18 sessões de treinamento os jogadores: "tem uma forma irregular de comportamento, procurando a posição ótima e oferecendo ao portador da bola quase sempre a possibilidade de passe. No entanto a situação não era difícil".

Em relação à equipe $M G$ houve um aumento significativo $(p=0,034)$ no total de pontos obtidos do pré-teste (138) para o pós-teste (178). A mediana apresentou um valor de 6 pontos no préteste. No pós-teste o valor da mediana foi de 7 pontos. Estes valores das medianas do pré-teste e do pós-teste, de acordo com o gabarito do
KORA:OO

convergente,

significa, respectivamente, que os jogadores: "apesar de estarem em situação de uma posição tática difícil, procuraram freqüentemente uma posição ótima para darem possibilidades do passe". Em seguida as 18 sessões de treinamento os jogadores: "tem procurado quase sempre a posição ótima para que o colega em posse de bola tenha a opção de passe, no entanto a situação não era muito difícil".

$\mathrm{Na}$ Tabela 2 estão os valores computados em relação ao parâmetro $\mathrm{OO}$ divergente (criatividade tática), referentes ao o pré-teste e o pós-teste das duas equipes.

Tabela 2. Resultado do pré-teste e do pós-teste para conhecimento tático processual $\mathrm{OO}$ divergente (criatividade tática).

\begin{tabular}{lccccc}
\hline & \multicolumn{2}{c}{ Equipe MA } & \multicolumn{2}{c}{ Equipe MG } \\
& Pré-Teste & Pós-Teste & Pré-Teste & Pós-Teste \\
\hline Pontos & 136 & 173 & 214 & 266 \\
Mediana & 3 & 5 & 5 & 7 \\
Valor $p$ & & $0,024^{*}$ & & \multicolumn{3}{c}{$0,028^{*}$} \\
\hline
\end{tabular}

$\mathrm{Na}$ equipe MA houve um aumento significativo $(p=0,024)$ no total de pontos obtidos do pré-teste (138) para o pós-teste (178). A mediana apresentou um valor de 3 pontos no pré-teste. Já no pós-teste o valor da mediana foi de 5 pontos. Estes valores das medianas do pré-teste e do pós-teste, de acordo com o gabarito do KORA:OO divergente, significa, respectivamente, que os jogadores: "demonstram em regra gerais soluções, dentro do repertório padrão, que aparecem freqüentemente. Ocasionalmente as procuras temporais de ótimas posições tiveram um pouco de novidade". Após as 18 sessões de treinamento os jogadores: "demonstram uma diferente solução que não são dentro do repertório padrão, mas que já apareceram. As procuras temporais de ótimas posições tiveram sim novidade".

Em referência a equipe $M G$ houve um aumento significativo $(p=0,028)$ no total de pontos obtidos do pré-teste (214) para o pós-teste (266). A mediana apresentou um valor de 5 pontos no pré-teste. No pós-teste o valor da mediana foi de 7 pontos. Estes valores das medianas do préteste e do pós-teste, de acordo com o gabarito do KORA:OO divergente, significa, respectivamente, que os jogadores: "demonstram uma diferente solução que não são dentro do repertório padrão, mas que já apareceram. As procuras temporais de ótimas posições tiveram sim novidade". Após as 18 sessões de treinamento os jogadores: "demonstraram duas diferentes soluções que não 
foram originais (fora do comum), mas que aparecem de forma esporádica. As procuras temporais de ótimas posições foram sempre surpresas".

$\mathrm{Na}$ Tabela 3 constam os valores apurados em relação ao parâmetro $\mathrm{RE}$ convergente (inteligência tática), referentes ao pré-teste e 0 pós-teste das duas equipes.

Tabela 3. Resultado do pré-teste e do pós-teste para conhecimento tático processual RE convergente (inteligência tática).

\begin{tabular}{lcccc}
\hline & \multicolumn{2}{c}{ Equipe MA } & \multicolumn{2}{c}{ Equipe MG } \\
& Pré-Teste & Pós-Teste & Pré-Teste & Pós-Teste \\
\hline Pontos & 228 & 251 & 183 & 251 \\
Mediana & 6 & 6 & 5 & 7 \\
Valor $p$ & 0,334 & & $0,001^{*}$ \\
\hline
\end{tabular}

Não houve diferença significativa $(p=0,334)$ na equipe $M A$ em relação ao parâmetro $R E$ convergente. A equipe conseguiu no pré-teste 228 pontos e no pós-teste 251. A mediana apresentou um valor de 4 pontos no pré-teste. No pós-teste 0 valor da mediana foi de 5 pontos.

Em relação à equipe $M G$ houve um aumento significativo $(p=0,001)$ no total de pontos obtidos do pré-teste (183) para o pós-teste (251). A mediana apresentou um valor de 5 pontos no préteste. No pós-teste o valor da mediana foi de 7 pontos. Estes valores das medianas do pré-teste e do pós-teste, de acordo com o gabarito do KORA:RE convergente, significa, respectivamente, que os jogadores: "apresentaram várias decisões críticas, mas nenhuma errada. As situações eram de dificuldade média". Em seguida as 18 sessões de treinamento os jogadores: "utilizaram quase sempre o espaço de maneira ótima, mas enfrentam um defensor mais fraco quando apareceram as situações de jogo".

$\mathrm{Na}$ Tabela 4 estão os valores computados em relação ao parâmetro RE divergente (criatividade tática), referentes ao o pré-teste e o pós-teste das duas equipes.

Tabela 4. Resultado do pré-teste e do pós-teste para conhecimento tático processual $R E$ divergente (criatividade tática).

\begin{tabular}{lccccc}
\hline & \multicolumn{2}{c}{ Equipe MA } & \multicolumn{2}{c}{ Equipe MG } \\
& Pré-Teste & Pós-Teste & Pré-Teste & Pós-Teste \\
\hline Pontos & 152 & 173 & 217 & 266 \\
Mediana & 4 & 5 & 6 & 7 \\
Valor $p$ & 0,283 & & & $0,008^{*}$ \\
\hline
\end{tabular}

O cálculo do teste de Wilcoxon não apontou diferença significativa $(p=0,283)$ na equipe MA em relação ao parâmetro $R E$ divergente. $A$ equipe conseguiu no pré-teste 152 pontos e no pós-teste 173. A mediana apresentou um valor de 4 pontos no pré-teste. No pós-teste o valor da mediana foi de 5 pontos.

$\mathrm{Na}$ equipe MG houve um aumento significativo $(p=0,008)$ no total de pontos obtidos do pré-teste (217) para o pós-teste (266). A mediana apresentou um valor de 6 pontos no pré-teste. No pós-teste 0 valor da mediana foi de 7 pontos. Estes valores das medianas do pré-teste e do pós-teste, de acordo com o gabarito do KORA:RE divergente, significa, respectivamente, que os jogadores: "demonstraram duas alternativas de soluções diferentes, que não foram pouco comuns, mas que aparecem na prática com pouca freqüencia. As descobertas dos espaços e de passes foram sempre surpresas". Depois das 18 sessões de treinamento os jogadores: "demonstraram duas alternativas de soluções diferentes, que não foram pouco comuns, mas que apareceram na prática com pouca freqüência. As descobertas dos espaços e dos passes foram sempre cheias de muita surpresa".

A equipe MA, com o seu processo de E-A-T apoiado no método analítico, conseguiu um desenvolvimento do conhecimento tático processual $\mathrm{OO}$ convergente e divergente, mas 0 mesmo não ocorreu em relação conhecimento tático RE convergente e divergente. Nos estudos realizados por Vilhena (2007) e Vilhena; Greco (2009) foi verificado melhora no parâmetro OO e $\mathrm{RE}$ convergente, ao contrário do divergente. Morales (2007), mais Morales; Greco (2007), observaram aumento do conhecimento tático processual convergente e divergente, no parâmetro OO, com treinos centrados no desenvolvimento da técnica. Tal efeito não foi verificado no conhecimento tático processual RE.

A equipe MG, com o seu processo de E-A-T apoiado no método global, obteve um desenvolvimento de todos os parâmetros táticos avaliados pelo KORA: conhecimento processual OO convergente $e$ divergente, mais $O R E$ convergente e divergente. No estudo de Vilhena (2007) não houve aprimoramento de nenhum dos parâmetros táticos avaliados pelo KORA, após as dezoito sessões de treino baseadas no método global.

Quando comparado com os processos analíticos, o método global tem se mostrado mais consistente em relação ao desenvolvimento do conhecimento tático e apresentado melhores resultados no decorrer do tempo. Pois, além de exigir uma atitude tática decisória executada visivelmente pelo gesto técnico, apresenta uma maior motivação para o jogador, uma vez que não é tão centrado no professor (XAVIER, 1986; GRECO, 1998; GRECO, 2001; VILHENA, 2007; 
PEREIRA et al., 2009). O método analítico tem como indicativo o refinamento do gesto técnico, isto quando se tem o intuito de efetuar a ação de acordo com o modelo biomecânico ideal de execução, seja de forma aproximada ou integral (XAVIER, 1986; GRECO, 1998; GRECO, 2001; COUTINHO; SILVA, 2009).

Os professores/treinadores ao fazerem uso da abordagem tradicional, do método global, do analítico e do misto (COSTA; NASCIMENTO, 2004; COSSIO-BOLAÑOS et al., 2009; NASCIMENTO et al., 2009), devem considerar relevante $\mathrm{O}$ uso de métodos baseados no emprego de novas pedagogias referentes ao ensino-aprendizagem-treinamento dos JEC, permitindo um adequado desenvolvimento do conhecimento tático ( CORRÊA; SILVA; PAROLI, 2004; COSTA; NASCIMENTO, 2004; COSSIOBOLAÑOS et al., 2009; MORALES; GRECO, 2007; NASCIMENTO et al., 2009; MESQUITA et al., 2009; REVERDITO; SCAGLIA; PAES, 2009; MORALES; GRECO; ANDRADE, 2009; GRECO; MEMMERT; MORALES, 2010; PINHO et al., 2010; SANTANA; RIBEIRO, 2010). O processo de ensino dos JEC não deve procurar somente a transmissão de um conjunto de habilidades técnicas. Ele também deve oportunizar a formação do jogador inteligente e criativo com capacidade de tomada de decisões e de adaptações às condições inerentes a lógica do jogo (GARGANTA, 1995; GRECO; BENDA, 1998; COSTA; NASCIMENTO; 2004; MESQUITA, 2005; GRECO, 2004; GRECO, 2006; MEMMERT; ROTH, 2007; MESQUITA et al., 2009; REVERDITO; SCAGLIA; PAES, 2009; $\underline{\text { RIBAS, }}$ 2010; PINHO et al., 2010).

A reflexão sobre as práticas pedagógicas tradicionais e o uso de metodologias com abordagem decisória, centrada nos processos cognitivos, nos JEC, propicia aos praticantes, inclusive aos que apresentam dificuldades motoras, um melhor resultado em suas tomadas de decisão. As ações tático-técnicas são expressas com maior integração com o objetivo da equipe e mais adequadas às características $e$ particularidades da situação do jogo (MORALES; GRECO, 2007). Assim, o processo de E-A-T deve focalizar os aspectos táticos-estratégicos do jogo mediante a manipulação dos constrangimentos da tríade pessoa-tarefa-ambiente (DUARTE, 2009; NITSCH, 2009).

O desenvolvimento do conhecimento tático processual propicia aos praticantes da modalidade desportiva a percepção positiva do próprio progresso e uma relação afetuosa com a modalidade exercitada (MORALES; GRECO, 2007). Para tal, os praticantes devem ter liberdade processual, decorrendo na geração de uma ação intencional e autônoma, efeito da percepção de indicadores especificadores, dos sinais relevantes, disponível no contexto situacional do jogo (MESQUITA, 2005; GRECO, 2009a; GRECO, 2009b).

\section{Conclusões}

A partir dos resultados apurados e dentro das limitações do presente estudo foi possível observar que, no processo de ensinoaprendizagem-treinamento, $\mathrm{o}$ método analítico não propiciou um pleno desenvolvimento do conhecimento tático processual. Deste modo, não houve a expressão de decisões táticas de forma inteligente e criativa ao Oferecer-se e Orientar-se e ao Reconhecer Espaços. Já o método de ensino global permitiu o desenvolvimento pleno do conhecimento tático processual divergente e convergente, em ambos os parâmetros avaliados: Oferecer-se e Orientar-se e Reconhecer Espaços.

Para novos estudos sugere-se o uso da abordagem qualitativa (isolada ou combinada com a quantitativa). O participante (voluntário) poderá explanar a respeito do próprio desempenho e da motivação no treinamento referente ao método de ensino aplicado.

Em síntese, recomenda-se futuros estudos considerando o conhecimento tático produto de distintos métodos de ensino, nos diversos Jogos Esportivos Coletivos, a partir de diferentes faixas etárias, anos de prática, níveis de habilidade, rendimento coletivo (classificações finais de diferentes equipes em um campeonato), mensuração em diferentes etapas do treinamento anual e por fim a combinação de métodos de ensino e inversão na ordem de aplicação destes. Assim, será possível deslindar as contribuições destes métodos no processo de ensinoaprendizagem-treinamento.

\section{Referências}

BRITO, R.F.; VANZIN, T.; ULBRICHT, V.

Reflexões sobre o conceito de criatividade: sua relação com a biologia do conhecer. Ciências \& Cognição, Rio de Janeiro, v.14, n.3, p.204-213, 2009.

COLLET, C.; NASCIMENTO, J.V.; RAMOS, M.H.K.P.; DONEGÁ, A. Processo de ensinoaprendizagem-treinamento no voleibol infantil masculino em Santa Catarina. Revista da

Educação Física/UEM, Maringá, v.18, n.2, p.147159, 2007.

CORRÊA, U.C.; SILVA, A.S.; PAROLI, R. Estudo de diferentes métodos de ensino na 
aprendizagem do futebol de salão. Motriz, Rio Claro, v.10, n.2, p.79-88, 2004.

COSSIO-BOLAÑOS, M.A.; PASCOAL, E.H.F.; PAES, R.R.; ARRUDA, M. Métodos de ensino nos jogos esportivos. Movimento \& Percepção, Espírito Santo do Pinhal, v.10, n.15, p. 264-273, 2009.

COSTA, L.C.A.; NASCIMENTO, J.V. O ensino da técnica e da tática: novas abordagens metodológicas. Revista de Educação Física/UEM, Maringá, v.15, n.2, p.49-56, 2004.

COUTINHO, N.F.; SILVA, S.A.P.S. Conhecimento e aplicação de métodos de ensino para os jogos esportivos coletivos na formação profissional em educação física. Movimento, Porto Alegre, v.15, n.1, p.123-150, 2009.

DUARTE, A. O desenvolvimento da competência táctica no desporto: o papel dos constrangimentos no comportamento decisional. Motriz, Rio Claro, v.15, n.3, p.537-540, 2009.

EYSENCK, M.W.; KEANE, M.T. Psicologia cognitiva: um manual introdutório. 1. ed. Porto Alegre: Artes Médicas, 1994.

FERREIRA, H.B.; GALATTI, L.R.; PAES, R.R. Pedagogia do esporte: considerações pedagógicas e metodológicas no processo de ensino - aprendizagem do basquetebol. In: PAES, R.R.; BALBINO, H.F. Pedagogia do Esporte. Contextos e Perspectivas. Rio de Janeiro; Guanabara Koogan, 2005. p.123-136.

GARGANTA, J. Para uma teoria dos jogos desportivos colectivos. In: GRAÇA, A.; OLIVEIRA, J. $O$ ensino dos jogos desportivos. 1. ed. Porto: CEJD/FCDEF/Universidade do Porto, 1995. p.11-25.

GARGANTA, J.M. O ensino dos jogos desportivos coletivos. 1. ed. Porto Alegre: Perspectivas e Tendências, 1998.

GIACOMINI, S.D. Conhecimento tático declarativo e processual no futebol: estudo comparativo entre estudo de diferentes categorias e posições. 2007. 161f. (Mestrado em Educação Física: Treinamento Esportivo) Escola de Educação Física, Fisioterapia e Terapia Ocupacional da Úniversidade Federal de Minas Gerais. 2007.

GIACOMINI, S.D.; GRECO, P.J. Comparação do conhecimento tático processual em jogadores de futebol de diferentes categorias e posições.

Revista Portuguesa de Ciências do Desporto, Porto, v.8, n.1, p.126-136. 2008.
GIACOMINI, S.D.; SOARES, V.O.; SANTOS, H.F.; MATIAS, C.J.A.S. O conhecimento tático declarativo e processual em jogadores de futebol de diferentes escalões. Motricidade, Santa Maria da Feira, v.7, n.1, p.43-53, 2011.

GIMÉNEZ, A.M. Técnicas de enseñanza en la iniciación al baloncesto. 2. ed. Barcelona: INDE Publicaciones, 2005.

GRAÇA, A.; MESQUITA, I. A investigação sobre os modelos de ensino dos jogos esportivos coletivos. Revista Portuguesa de Ciências do Desporto, Porto, v.7, n.3, p.401-421, 2007.

GRECO, P.J. Iniciação Esportiva Universal Metodologia da iniciação esportiva na escola e no clube - Volume II. 1. ed. Belo Horizonte: UFMG, 1998.

GRECO, P.J. Métodos de ensino-aprendizagemtreinamento nos jogos esportivos coletivos. 2001. In: SILAMI, G.E.; LEMOS, M.L.K.; GRECO, P.J. Temas Atuais VI - Educação Física e Esportes. 1. ed. Belo Horizonte: Healt, 2001. p.48-72.

GRECO, P.J. Cogni(a)cão: conhecimento, processos cognitivos e modelos de ensinoaprendizagem-treinamento para o desenvolvimento da criatividade (tática). Revista Portuguesa de Ciências do Desporto, Porto, v.4, n.2 (Suplemento), p.56-59, 2004.

GRECO, P.J. Conhecimento tático-técnico: eixo pendular da ação tática (criativa) nos jogos esportivos coletivos. Revista Brasileira de Educação Física e Esporte, São Paulo, v.20, n.5, p.210-212. 2006.

GRECO, P.J. Percepção. In: SAMULSKI, M.D. Psicologia do Esporte: conceitos e novas perspectivas. 2. ed. Barueri: Editora Manole, p.57-84, 2009a.

GRECO, P.J. Tomada de Decisão. In: SAMULSKI, M.D. Psicologia do Esporte: conceitos e novas perspectivas. 2. ed. Barueri: Editora Manole, p.107-142, 2009b.

GRECO, P.J.; BENDA, R.N. Iniciação Esportiva Universal: da aprendizagem motora ao treinamento técnico - Volume 1. 1. ed. Belo Horizonte: UFMG, 1998.

GRECO, P.J.; MEMMERT, D.; MORALES, J.C.P. The effect of deliberate play on tactical performance in Basketball. Perceptual and Motor Skills, Missoula, v.110, n.3, p.849-856, 2010.

KRÖGER, C.; ROTH, K. Escola da bola: um abc para iniciantes nos jogos esportivos. 1. ed. São Paulo: Phorte, 2002. 
LIMA, C.O.V. Desenvolvimento do conhecimento tático declarativo e processual no processo de ensino-aprendizagemtreinamento do voleibol escolar. 2008. $166 f$. Dissertação (Mestrado em Ciências do Esporte) Escola de Educação Física, Fisioterapia e Terapia Ocupacional, Universidade Federal de Minas Gerais. Belo Horizonte, 2008.

LIMA, C.O.V.; MATIAS, C.J.A.S.; GRECO, P.J. O conhecimento tático produto de métodos de ensino combinados e aplicados em sequências inversas no voleibol. Revista Brasileira de Educação Física e Esporte, São Paulo, v.26, n.1, p. 129-147, 2012.

MATIAS, C.J.A.S.; GRECO, P.J. Análise de jogo nos esportes coletivos: a exemplo do voleibol. Revista Pensar a Prática, Goiânia, v.12, n.3, p.115, 2009.

MATIAS, C.J.A.S.; GRECO, P.J. Cognição e ação nos jogos esportivos coletivos. Ciências \& Cognição, Rio de Janeiro, v.15, n.1, p.252-271, 2010.

MEMMERT, D. Diagnostik taktischer leistungskomponenten: spieltestsituationen und konzeptorientierte expertenratings (Componentes táticos de diagnósticos de rendimento: teste de situações de jogo e avaliação através do conceitos de experts). 2002. Tese (Doutorado em Ciências do Esporte) Institut für Sport und Sporrtwissenschaft, Universidade de Heidelberg. Heidelberg, 2002.

MEMMERT, D.; ROTH, K. The effects on nonspecifc and specifc on tactical creativity in tem ball sports. Journal of Sports Sciences, London, v.25, n.12, p.1423-1432, 2007.

MENDES, J.C. O processo de ensinoaprendizagem-treinamento do handebol no estado do Paraná: estudo da categoria infantil. 2006. 95f. Dissertação (Mestrado em Educação Física: Teoria e Prática Pedagógica em Educação Física) - Centro de Educação Física e Desporto, Universidade Federal de Santa Catarina. Florianópolis, 2006.

MESQUITA, I. Valorização da aprendizagem autônoma no treino de crianças e jovens. Revista Perfil, Porto Alegre, v.7, n.8, p.15-16, 2005.

MESQUITA, I.M.R.; PEREIRA, F.R.M.; GRAÇA, A.B.S. Modelos de ensino dos jogos desportivos: investigação e ilações para a prática. Motriz, Rio Claro, v.15, n.4, p. 944-954, 2009.

MORALES, J.C.P. Processo de ensinoaprendizagem-treinamento no basquetebol: influência no conhecimento tático processual. 2007. 176f. (Mestrado em Educação Física:
Treinamento Esportivo) - Escola de Educação Física, Fisioterapia e Terapia Ocupacional, Universidade Federal de Minas Gerais. Belo Horizonte, 2007.

MORALES, J.C.P.; GODINHO, E.S.; MATIAS, C.J.A.S.; REIS, A.R.; GRECO, P.J. Processo de ensino-aprendizagem-treinamento no minibasquetebol. Fitness \& Performance Journal, Rio de Janeiro, v.8, n.5, p.349-359, 2009.

MORALES, J.C.P; GRECO, P.J. A influência de diferentes metodologias de ensino-aprendizagemtreinamento no basquetebol sobre o nível de conhecimento tático processual. Revista Brasileira de Educação Física e Esporte, São Paulo, v.21, n.4, p.291-299. 2007.

MORALES, J.C.P.; GRECO, P.J.; ANDRADE, R.L. A description of the teaching-learning processes in basketball and their effects on procedural tactical knowledge. Revista de Psicología del Deporte, Palma de Malorca, v.18, n.3, p.469-473, 2009.

NASCIMENTO, J.V.; RAMOS, V.; MARCON, D,; SAAD, M.A.; COLLET, C. Formação acadêmica e intervenção pedagógica nos esportes. Motriz, Rio Claro, v.15, n.2, p.358-366, 2009.

NITSCH, J.R. Ecological approaches to Sport Activity: A commentary from an action-theoretical point of view. International Journal of Sport Psychology, Roma, v.40, n.1, p.152-176. 2009.

OLIVEIRA, A.F.; BELTRÃO, B.F.; SILVA, F.V. Metacognição e hemisfericidade em jovens atletas: direcionamento para uma pedagogia de ensino desportivo. Revista Paulista de Educação Física, São Paulo, v.17, n.1, p.5-15, 2003.

OLIVEIRA, V.; PAES, R.R. Ciência do basquetebol. Pedagogia e metodologia da iniciação à especialização. 1. ed. Londrina: Midiograf, 2004.

PAGANO, M.; GAUVREAU, K. Princípios de Bioestatística. 1. ed. São Paulo: Thomson Learning, 2006.

PEREIRA, F.; MESQUITA, I.; GRAÇA, A. A autonomia e a responsabilização dos praticantes no treino em Voleibol. Estudo comparativo de treinadores em função do gênero. Motriz, Rio Claro, v.9, n.1, p.64-78, 2009.

PINHO, S.T.; ALVES, D.M.; GRECO, P.J.; SCHILD, J.F.G. Método situacional e sua influência no conhecimento tático processual de escolares. Motriz, Rio Claro, v.16, n.3, p.580-590, 2010. 
PINTO, F.S; SANTANA, W.C. Iniciação ao futsal: as crianças jogam para aprender ou aprendem para jogar? Lecturas Educación Física y

Deportes, Buenos Aires, v.10, no. 85, p.1-1, 2005.

RIBAS, J.F.M. Praxiologia Motriz:

instrumentalizando a prática pedagógica para o ensino dos esportes coletivos. Motriz, Rio Claro, v.16, n.1, p.240-250, 2010.

REVERDITO, R.S.; SCAGLIA, A.J.; PAES, R.R.; Pedagogia do esporte: panorama e análise conceitual das principais abordagens. Motriz, Rio Claro, v.15, n.3, p.600-610, 2009.

SAAD, M.A. Estruturação das sessões de treinamento técnico-tático nos escalões de formação do Futsal. 2002. 101f. Dissertação (Mestrado em Educação Física: Teoria e Prática Pedagógica em Educação Física) - Centro de Educação Física e Desporto, Universidade Federal de Santa Catarina. Florianópolis, 2002.

SANTANA, W.C.; RIBEIRO, D.A. Idades de início de atletas de futsal de alto rendimento na prática sistemática e em competições federadas da modalidade. Revista Pensar a Prática, Goiânia, v.13, n.2, p.1-17, 2010.

STERNBERG, R.J. Psicologia Cognitiva. 4. ed. Porto Alegre: ArtMed. 2008.

STEFANELLO, J.M.F. A participação da criança no desporto competitivo: uma tentativa de operacionalização e verificação empírica da proposta teórica de Urie Brofenbrenner. 1999. 232f. Tese (Doutorado em Educação Física) Faculdade de Ciências do Desporto e de Educação Física, Universidade de Coimbra. Coimbra, 1999.

TAVARES, F. Análise da estrutura e dinâmica do jogo nos jogos desportivos. In: BARBANTI, J.; BENTO, J.; MARQUES, A.; AMADIO, A. Esporte e Atividade Física. Interação entre Rendimento e Qualidade de Vida. 1. ed. São Paulo: Manole. 2002. p.129-143.

THOMAS, J.R.; NELSON, J.K. Métodos de Pesquisa em Atividade Física. 3. ed. Porto Alegre: ArtMed. 2002.

VILHENA, M.S. Processo de ensinoaprendizagem-treinamento no futsal: influência no conhecimento tático-processual. 2007. 208f. (Mestrado em Educação Física: Treinamento Esportivo) - Escola de Educação Física, Fisioterapia e Terapia Ocupacional, Universidade Federal de Minas Gerais. Belo Horizonte, 2007.

VILHENA, M.S.; GRECO, P.J. A influência dos métodos de ensino-aprendizagem-treinamento no desenvolvimento da inteligência e criatividade tática em atletas de futsal. Revista Brasileira de Educação Física e Esporte, São Paulo, v.23, n.3, p.297-307, 2009.

XAVIER, T.P. Métodos de ensino em educação física. 1. ed. São Paulo: Manole, 1986.

Apoio: Capes; CNPq.

\section{Endereço:}

Valmo José Penna Moreira

Escola de Educação Física, Fisioterapia e Terapia Ocupacional, UFMG

Av. Antônio Carlos, 6627 Campus Pampulha

Belo Horizonte MG Brasil

31270-901

Telefone: +55 (31) 3409-23.29

e-mail: valmojose@gmail.com

Recebido em: 7 de fevereiro de 2011.

Aceito em: 6 de fevereiro de 2013.

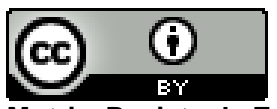

Motriz. Revista de Educação Física. UNESP, Rio Claro, SP, Brasil - elSSN: 1980-6574 - está licenciada sob Creative Commons - Atribuicão 3.0 